\title{
Healthcare-associated infections in intensive care units in Taiwan, South Korea, and Japan: recent trends based on national surveillance reports
}

Cho-Han Chiang ${ }^{1 \dagger}$, Sung-Ching Pan ${ }^{2 \dagger}$, Tyan-Shin Yang ${ }^{1}$, Keisuke Matsuda ${ }^{3}$, Hong Bin Kim ${ }^{4,5}$, Young Hwa Choi ${ }^{6}$, Satoshi Hori ${ }^{7}$, Jann-Tay Wang ${ }^{1,2,8}$, Wang-Huei Sheng ${ }^{1,2,8}$, Yee-Chun Chen ${ }^{1,2,8,9^{*}}$, Feng-Yee Chang ${ }^{10}$ and Shan-Chwen Chang ${ }^{1,2}$

\begin{abstract}
Background: Sustainable systematic interventions are important for infection prevention and control (IPC). Data from surveillance of healthcare-associated infections (HAl) provides feedback for implementation of IPC programs. To address the paucity of such data in Asia, we searched for national HAl surveillance and IPC programs in this region.

Methods: Data were analysed from open access national surveillance reports of three Asian countries: Taiwan, South Korea and Japan from 2008 to 2015. National IPC programs were identified.

Results: There were differences among the countries in surveillance protocols, hospital coverage rates, and national IPC policies and programs. Nevertheless, there was a 53.0\% reduction in overall HAI over the 8-year period. This consisted of a decrease from 9.34 to 5.03 infections per 1000 patient-days in Taiwan, from 7.56 to 2.76 in Korea, and from 4.41 to 2.74 in Japan (Poisson regression, all $p<0.05$ ). Across the three countries, Escherichia coli and Candida albicans were the major pathogens for urinary tract infection. Staphylococcus aureus, Acinetobacter baumannii and Enterococcus faecium were common bloodstream pathogens. For pneumonia, S. aureus, A. baumannii, Pseudomonas aeruginosa, and Klebsiella pneumoniae were the predominant pathogens, with considerable country differences. There was a $64.6 \%$ decrease in the number of isolates of methicillin-resistant $S$. aureus, 38.4\% decrease in carbapenemresistant $P$. aeruginosa and $49.2 \%$ decrease in carbapenem-resistant A. baumannii (CRAB) in Taiwan (all $p<0.05$ ), and similarly in Korea with the exception of CRAB (30.5 and 50.4\% reduction, respectively, both $p<0.05$ ).
\end{abstract}

Conclusion: We found a significant decrease in $\mathrm{HAl}$ across the three countries in association with sequential multifaceted interventions such as hand hygiene, care bundles, and antimicrobial stewardships. Further regional collaboration could be forged to develop joint strategies to prevent HAl.

Keywords: Healthcare-associated infections, National surveillance, Antimicrobial resistance, National policy, Infection prevention and control program

\footnotetext{
* Correspondence: yeechunchen@gmail.com

${ }^{\dagger}$ Cho-Han Chiang and Sung-Ching Pan contributed equally to this work.

${ }^{1}$ College of Medicine, National Taiwan University, Taipei, Taiwan

${ }^{2}$ Department of Internal Medicine, National Taiwan University Hospital, Taipei,

Taiwan

Full list of author information is available at the end of the article
}

(c) The Author(s). 2018 Open Access This article is distributed under the terms of the Creative Commons Attribution 4.0 International License (http://creativecommons.org/licenses/by/4.0/), which permits unrestricted use, distribution, and reproduction in any medium, provided you give appropriate credit to the original author(s) and the source, provide a link to the Creative Commons license, and indicate if changes were made. The Creative Commons Public Domain Dedication waiver (http://creativecommons.org/publicdomain/zero/1.0/) applies to the data made available in this article, unless otherwise stated. 


\section{Background}

The European Healthcare-associated Infections Surveillance Network (HAI-net) is one of the most coordinated and comprehensive surveillance systems that monitors healthcare-associated infections (HAI). By centralizing data on antimicrobial use, HAI incidence, and HAI point prevalence, HAI-net builds a regional landscape that allows inter-country comparison and provides feedback for implementation of regional infection prevention and control (IPC) guidelines [1].

With its high burden of HAI, Asia stands to benefit by learning from such a surveillance network. A recent meta-analysis reported a pooled HAI incidence density of 20 cases per 1000 intensive care unit-days in Southeast Asia [2]; studies in India and China found pooled ventilator-associated pneumonia of 9.4 and 20.8 cases per 1000 ventilator-days, respectively [3, 4]. Establishing surveillance in Asian countries, either as national or regional collaborations, might help relevant stakeholders to identify systemic gaps and establish improvements in IPC.

The current understanding of HAI surveillance in Asia remains limited despite the relatively large numbers of IPC conducted in Asia [2, 5]. Likewise, national scale data documenting the regional HAI epidemiology in Asia is scarce [2]. To better understand the current state of HAI surveillance and IPC programs in Asia, we searched for data on existing national HAI surveillance programs. Three Asian countries: Taiwan [6, 7], South Korea [8-10], and Japan [11] were found to conduct nationwide HAI surveillance systems. The present study is based on data derived from open access reports from the surveillance systems of these countries. They include temporal trends of HAI in intensive care units (ICUs), the major causative pathogens and antimicrobial resistance (AMR). Nationally implemented IPC policies were also reviewed to gain insights on important interventions instituted in these three countries.

\section{Methods}

\section{Study design and source of data}

We performed a Google and PubMed search to determine the existing national HAI surveillance systems in Asian countries using the following terms "national nosocomial infection surveillance" or "national healthcare-associated infection surveillance" in combination with specific country names. The inclusion criteria were: English language, open access data or PubMed publications, annual data containing either point prevalence or yearly surveillance for 5 or more years. Data from the national HAI surveillance systems were retrospectively retrieved and analysed.

National surveillance systems of Taiwan, South Korea, and Japan

Three national HAI surveillance systems met the study criteria. These were the Taiwan Nosocomial Infection
Surveillance (TNIS), Korean National Healthcare-associated Infection Surveillance (KONIS), and Japan Nosocomial Infection Surveillance (JANIS). Each system prospectively collects data on the incidence, causative pathogens, and antimicrobial resistance of HAI in ICUs. HAI data are stratified by infection site: urinary tract infection (UTI), bloodstream infection (BSI), hospital-acquired pneumonia (HAP); by device-use: catheter-associated urinary tract infection (CAUTI), central line-associated bloodstream infection (CLABSI), and ventilator-associated pneumonia (VAP); and by type of hospital (in Taiwan and South Korea). These HAI cases and categories are in accord with the definitions of the US National Healthcare Safety Network (NHSN) system with minor modifications to account for differences in clinical or laboratory practice and national policies.

\section{Data collection}

Demographic data for each country were retrieved from the World Bank and their respective national authorities. Hospital and ICU composition of each surveillance system were recorded from their official web portals. Annual data of overall HAI, device-associated HAI, causative pathogens, and rates of AMR of important bacteria were also retrieved from the three surveillance systems. We selected the study period as 2008 to 2015 because data for this period were accessible across all three systems. National-scale IPC policies and programs were obtained by online search or in consultation with experts from the three countries.

\section{Data analysis}

Incidence densities of overall HAI were determined as pooled means of UTI, BSI, and HAP rates, and calculated as overall HAI episodes per 1000 patient-days. Analysis of device-associated HAI included CAUTI, CLABSI, and VAP. For Taiwan and Korea, incidence densities of device-associated HAI were calculated as device-associated infection episodes per 1000 device-days. For Japan, device-associated HAI were analysed by device-associated infection episodes per 1000 patient-days which made Japanese data incompatible with data from other countries. Causative pathogens were classified at the species level. AMR proportions of selected pathogens were calculated as number of antimicrobial-resistant isolates divided by the total number of isolates of the same species.

\section{Statistical analysis}

A Poisson regression model was used to assess the temporal trends of HAI incidence. Linear regression was used to analyse the trends in AMR isolates, using the STATA statistical program (version 14.0 Texas, USA). A $P$ value $<0.05$ was considered statistically significant. 


\section{Results}

Characteristics of Taiwan, South Korea and Japan's National Surveillance Systems

The characteristics of the national HAI surveillance systems of Taiwan, South Korea, and Japan are summarised in Table $1[6,8,11]$. The type, size and proportion of hospitals enrolled in the national surveillance varied among the countries. Taiwan included medical centres and regional hospitals classified according to hospital accreditation. Most of them had hospital beds of 300 beds or more. Korea and Japan included hospitals with more than 300 and 200 beds, respectively. The hospital coverage and participation rates were 21.2 and $100.0 \%$ in Taiwan, 18.0 and $38.6 \%$ in Korea, and 1.9 and $6.8 \%$ in Japan, respectively. A total of 472, 169 and 163 ICUs were enrolled in Taiwan, Korea and Japan, respectively. The number of participating hospitals and ICUs in all three countries during the study period has expanded (Additional file 1: Table S1) [6, 8, 11]. Categorization of HAI was different in JANIS, which presented only UTI, CLABSI and VAP. Infection incidence was also calculated differently as episodes per 1000 patient-days.

\section{National infection control policies or programs and HAI trends across Taiwan, South Korea, and Japan}

Numerous independent changes, aimed at improving surveillance and compliance, were made for national IPC policies, programs, or practices in each country (Fig. 1). Additional file 2: Table S2 summarised the details of national IPC programs in the past two decades by country. For example, during the study period hand hygiene, care bundles, hospital environment hygiene program and antimicrobial stewardship were the main interventions implemented in Taiwan. The hand hygiene program adapted the WHO multimodal strategies with particular emphasis on alcohol-based hand rub at the point of care. The care bundles program aimed to prevent CAUTI, CLABSI, and VAP. On the other hand, Korea and Japan enforced IPC practices by legislating and mandating IPC in hospitals. Incentives in terms of reimbursement 1.8-2.7 US dollars and 10 US dollars per admission were given to hospitals who met IPC standards in Korea and Japan, respectively. All three countries mandated assignment of infection control personnel. They also implemented formal and structured antimicrobial stewardship programs, which include surveillance of AMR pathogens and regulations of antimicrobial use.

\section{Overall HAl rates}

All three countries experienced a significant reduction of approximately $50 \%$ in HAI rates by the end of the study period. The incidence density in Taiwan decreased by 46.2\% from 9.3 to 5.0 infections per 1000 patient-days; in Korea HAI declined by $63.1 \%$ from 7.6 to 2.8 , and in Japan by $38.6 \%$ from 4.4 to 2.7 (Poisson regression, all $p<0.05$ ) (Fig. 1).

There was a significant reduction in device-associated HAI at all sites of infection in Taiwan and Korea $(p<0.05)$ (Fig. 2). Japan had low rates of CAUTI and CLABSI (presented as infections per 1000 patient-days) that persisted over the 8-year period. The most remarkable change was noted for CAUTI in Korea, with an $81.3 \%$ decrease from 4.8 to 0.9 infections per 1000 device-days $(P<0.05)$. All three countries experienced a similar trend in VAP during the study period with a $57.7 \%$ reduction from 2.6 to 1.1 infections per 1000 device-days in Taiwan.

\section{Causative pathogens}

The distributions of the top five (or four for Japan) causative pathogens according to country and site of infection in 2015 are shown in Table 2. For Taiwan and Korea, UTI, BSI and HAP data were presented; for Japan, UTI, CLABSI and VAP data were presented. A more comprehensive list of pathogens is shown in Additional file 3: Table S3, Additional file 4: Table S4, and Additional file 5: Table S5.

Escherichia coli and Candida albicans were included in the top five organisms causing UTI in all three countries. E. coli and C. albicans constituted 19.8 and 16.9\%, 17.6 and 12.6, 37.6 and 7.9\% of UTI for Taiwan, Korea, and Japan, respectively (Table 2). Along with Candida albicans, non-albicans Candida species and yeast-like organisms constituted $31.4 \%$ of the urinary tract pathogens in Taiwan. In Korea, 23.4\% of the UTI were due to Candida species (Additional file 3: Table S3).

Staphylococcus aureus was a major pathogen of BSI. The rates were $14.2 \%$ in Korea, $13.0 \%$ in Japan, and $6.5 \%$ in Taiwan (Table 2). Along with S. aureus, Staphylococcus epidermidis and coagulase-negative staphylococci constituted $38.8 \%$ of the CLABSI isolates in Japan. There were major differences among the countries in the distribution of other predominant pathogens. Acinetobacter baumannii and E. faecium were the predominant BSI pathogens in Taiwan and Korea. Major Candida species constituted $12.1 \%$ of the BSI isolates in Taiwan and $12.9 \%$ in Korea (Additional file 4: Table S4).

$S$. aureus, $P$. aeruginosa and $K$. pneumoniae were the predominant pathogens for HAP across all three countries (Table 2). Interestingly, A. baumannii was predominant in Taiwan and Korea but not in Japan, similar to the observation for BSI. For Taiwan and Korea, these four pathogens comprised 65.7 and $81.2 \%$ of the HAP isolates, respectively.

\section{Antimicrobial resistance}

Higher AMR rates were noted in Korea than in Taiwan (Fig. 3). The data for Japan were incomplete for several study years and are not shown in the figures. There was 
Table 1 Demographics and national surveillance systems of Taiwan, South Korea and Japan

\begin{tabular}{|c|c|c|c|}
\hline Parameter & Taiwan & South Korea & Japan \\
\hline \multicolumn{4}{|l|}{ Country background } \\
\hline Population $^{a}$ & $23,433,753^{b}$ & $50,746,659^{c}$ & $127,276,000^{d}$ \\
\hline Income bracket ${ }^{\mathrm{e}}$ & High income & High income & High income \\
\hline GDP, US dollars & 571,736 million $^{f}$ & 1,530,750.92 million $^{9}$ & 4,872,136.95 million ${ }^{9}$ \\
\hline $\begin{array}{l}\text { Share of GDP on } \\
\text { national health expenditure }\end{array}$ & $6.3 \%^{f}$ & $7.6 \%^{h}$ & $10.7 \%^{\mathrm{h}}$ \\
\hline Number of hospitals ${ }^{a}$ & $486^{i}$ & $534^{j}$ & $7426^{k}$ \\
\hline Surveillance system & $\begin{array}{l}\text { Taiwan Nosocomial Infection } \\
\text { Surveillance (TNIS) }\end{array}$ & $\begin{array}{l}\text { Korean National Healthcare- } \\
\text { associated Infection Surveillance } \\
\text { System (KONIS) }\end{array}$ & $\begin{array}{l}\text { Japan Nosocomial Infection } \\
\text { Surveillance (JANIS) }\end{array}$ \\
\hline Year established & 2001 & 2006 & 2000 \\
\hline Authority & $\begin{array}{l}\text { Centers for Disease Control, } \\
\text { Ministry of Health and } \\
\text { Welfare, Taiwan }\end{array}$ & $\begin{array}{l}\text { Korea Centers for Disease } \\
\text { Control and Prevention }\end{array}$ & $\begin{array}{l}\text { Ministry of Health, Labor } \\
\text { and Welfare, Japan }\end{array}$ \\
\hline \multicolumn{4}{|l|}{ ICU Surveillance ${ }^{a}$} \\
\hline Number of hospitals enrolled & 103 & 96 & 143 \\
\hline Number of ICUs enrolled & 472 & 169 & 163 \\
\hline $\begin{array}{l}\text { Types of hospitals enrolled } \\
\text { (total number in the country) }\end{array}$ & $\begin{array}{l}\text { Medical Centers and Regional } \\
\text { hospitals }{ }^{\prime}(n=103)\end{array}$ & $\begin{array}{l}\text { Bed size }>900,700-899 \\
300-699(n=249)^{n}\end{array}$ & Bed size > $200(n=2100)$ \\
\hline Hospital coverage rate & $21.2 \%(103 / 486)$ & $18.0 \%(96 / 534)$ & $1.9 \%(143 / 7426)$ \\
\hline Hospital participation rate ${ }^{m}$ & $100.0 \%(103 / 103)$ & $38.6 \%(96 / 249)$ & $6.8 \%(143 / 2100)$ \\
\hline $\begin{array}{l}\text { Mandated standard ratio } \\
\text { of infection control personnel }\end{array}$ & $\begin{array}{l}1 \text { dedicated full-time certificated } \\
\text { IC nurse per } 300 \text { beds (basic) or } \\
\text { per } 250 \text { beds (optimal) } \\
1 \text { FTE qualified IC doctor per } \\
500 \text { beds (basic) or per } 300 \\
\text { beds (optimal) } \\
\text { For hospitals }>500 \text { beds: } 1 \text { FTE } \\
\text { IC medical technician (basic) } \\
\text { or } 1 \text { dedicated full-time } \\
\text { certificated IC medical technician } \\
\text { (optimal); } 1 \text { FTE IC medical } \\
\text { technician for hospitals with } \\
300-499 \text { beds (optimal) }\end{array}$ & $\begin{array}{l}1 \text { dedicated full-time IC nurse per } \\
200 \text { beds (basic) or per } 150 \text { beds } \\
\text { (optimal) } \\
1 \text { qualified IC doctor per } 300 \text { beds }\end{array}$ & $\begin{array}{l}1 \text { dedicated full-time certificated } \\
\text { IC nurse (at }>0.8 \text { FTE) } \\
1 \text { part-time IC doctor (at }>0.5 \text { FTE) } \\
1 \text { part-time IC medical technician } \\
\text { and } 1 \text { part-time pharmacist } \\
\text { (at }>0.5 \text { FTE) } \\
\text { Additional manpower for } \\
\text { antimicrobial stewardship }\end{array}$ \\
\hline \multicolumn{4}{|c|}{ Healthcare-associated infection data provided } \\
\hline Site-specific HAls & $\begin{array}{l}\text { UTI, BSI, HAP: episode } \\
\text { per } 1000 \text { patient-day }\end{array}$ & $\begin{array}{l}\text { UTI, BSI, HAP: episode } \\
\text { per } 1000 \text { patient-day }\end{array}$ & UTI: episode per 1000 patient-day \\
\hline Device-associated HAls & $\begin{array}{l}\text { CAUTI, CLABSI, VAP: episode } \\
\text { per } 1000 \text { device-day }\end{array}$ & $\begin{array}{l}\text { CAUTI, CLABSI, VAP: episode } \\
\text { per } 1000 \text { device-day }\end{array}$ & $\begin{array}{l}\text { CLABSI, VAP: episode per } 1000 \\
\text { patient-day }\end{array}$ \\
\hline Causative pathogens & $\begin{array}{l}\text { Top } 10 \text { of the most } \\
\text { common pathogens }\end{array}$ & $\begin{array}{l}99 \% \text { of all the causative } \\
\text { pathogens }\end{array}$ & Top 5 of the most common pathogens ${ }^{q}$ \\
\hline Antimicrobial-resistant pathogens & $\begin{array}{l}\text { MRSA, VRE, CRAB, CRPA, } \\
\text { CRE, CREC, CRKP }\end{array}$ & $\begin{array}{l}\text { MRSA, VRE, IRAB, IRPA, } \\
\text { CefR-KP, CipR-KP, CefR-EC, CipR-EC }\end{array}$ & MRSA \\
\hline
\end{tabular}

Abbreviations: BSI bloodstream infections, CAUTI catheter-associated urinary tract infection, CefR-EC cefotaxime-resistant Escherichia coli, CefR-KP cefotaxime-resistant Klebsiella pneumoniae, CipR-EC ciprofloxacin-resistant $E$. coli, CipR-KP ciprofloxacin-resistant $K$. pneumoniae, CLABSI central line-associated bloodstream infections, CRAB carbapanem (imipenem or meropenem)-resistant Acinetobacter baumannii, CRE carbapanem (imipenem, meropenem, or ertapenem)-resistant Enterobacteriaceae, CREC carbapanem (imipenem, meropenem, or ertapenem)-resistant E. coli, CRKP carbapanem (imipenem, meropenem, or ertapenem)-resistant $K$. pneumoniae, CRPA carbapanem (imipenem or meropenem)-resistant Pseudomonas aeruginosa, FTE full-time equivalent, GDP gross domestic product, HAI Healthcare-associated infections, HAP hospital-acquired pneumonia, IC infection control, IRAB imipenem-resistant $A$. baumannii, IRPA imipenem-resistant $P$. aerugonisa, MRSA methicillin-resistant Staphylococcus aureus, MSSA methicillin-susceptible S. aureus, UTI urinary tract infections, VAP ventilator-associated pneumonia, VRE vancomycin-resistant enterococci (Enterococcus faecalis or E. faecium) a 2014 data

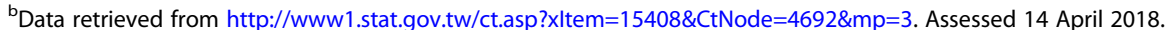

'Data retrieved from https://data.worldbank.org/country/korea-rep. Assessed 14 April 2018

${ }^{\mathrm{d}}$ Data retrieved from https://data.worldbank.org/country/japan?view=chart. Assessed 14 April 2018

e Data retrieved from World Bank Country and Lending Groups at https://datahelpdesk.worldbank.org/knowledgebase/articles/906519-world-bank-country-andlending-groups. Accessed 10 September 2018. For the current 2019 fiscal year, high-income economies are those with a gross national income per capita, calculated using the World Bank Atlas method of $\$ 12,056$ or more 
f 2016 data. Raw data NT dollars 17,152,093 million, converted to US dollars by ratio 30:1. Retrieved from https://www.mohw.gov.tw/lp-3781-2.html. Accessed 10 September 2018

${ }^{9} 2017$ data based on World Bank national accounts data, and Organization for Economic Co-operation and Development (OECD) National Accounts data. Retrieved from https://data.worldbank.org/indicator/NY.GDP.MKTP.CD. Accessed 10 September 2018

h 2017 data based on Organization for Economic Co-operation and Development (OECD) estimated data for Japan and provisional data for Korea. Retrieved from https://stats.oecd.org/Index.aspx?DataSetCode=SHA. Accessed 10 September 2018

'Data retrieved from https://www.mohw.gov.tw/dl-40542-045687b7-aa43-458c-ab70-e8ff24c5b1b3.html. Accessed 10 September 2018

jData retrieved from http://kosis.kr/eng/statisticsList/statisticsList_01List.jsp?vwcd=MT_ETITLE\&parentld=D\#SubCont. Accessed 10 September 2018

${ }^{k}$ Data retrieved from http://www.mhlw.go.jp/english/database/db-hh/2-2.html. Accessed 10 September 2018

'The data for Taiwan included medical centers and regional hospitals, which were classified according to hospital accreditation and covered only acute care hospitals

${ }^{\mathrm{m}}$ The hospital coverage rate was calculated as the number of participating hospitals divided by the total number of hospitals in the same year in each country. The hospital participation rate was calculated as the number of participating hospitals divided by the total number of hospitals to be enrolled in each surveillance system

In terms of surveillance, the requirement for participation in KONIS was 1 full-time infection control nurse over 200-bed size hospital. Regarding the mandatory personnel requirement, this regulation has been launched as a financial incentive program since 2016, as described in Additional file 2: Table S2

oData available at https://www.cdc.gov.tw/professional/info.aspx?treeid=beac9c103df952c4\&nowtreeid=bd387fa55fef03f0\&tid=FED32554F2B55D11. Accessed September 10, 2018

${ }^{\mathrm{P}}$ Infection prevention and control incentive through reimbursement policies was revised in 2010, 2012 and 2018, as described in Additional file 2: Table S2. Since 2012, each hospital is reimbursed 1000 JPY (about 10 USD) per patient per admission if it fulfills the Ministry of Health, Labor and Welfare requirements which mandated one dedicated full-time certificated ICN (at $>0.8 \mathrm{FTE}$ ), one part-time ICD (at $>0.5 \mathrm{FTE}$ ), one part-time IC pharmacist and one part-time medical technician/microbiologist (at >0.5 FTE). Since 2018, reimbursement policies per admission included three parts. It provides 3900 JPY (about 39 USD) per admission for infection prevention and control incentive at a major hospital, or $1000 \mathrm{JPY}$ for a small hospital. Additional $1000 \mathrm{JPY}$ was reimbursed if this hospital participates a local IPC network incentive. Another 1000 JPY was reimbursed for AS incentive. For hospitals with AS incentive, it mandates the following manpower in addition to 2012 requirements: one part-time doctor mainly for AS (at $>0.5 \mathrm{FTE}$ ), one full-time ICP either a certificated ICN or IC pharmacist or medical technician ${ }^{\mathrm{q}}$ MRSA and MSSA are listed as separate pathogens

a significant decrease in the number of isolates of methicillin-resistant S. aureus (MRSA) from 2008 to 2015. This included a $64.6 \%$ reduction in Taiwan and $30.5 \%$ in Korea $(p<0.05)$ (Fig. 3a). The proportion of MRSA among all S. aureus isolates in 2015 remained high in Korea $(83.1 \%)$, while it decreased in Taiwan by $12.3 \%$ from $79.9 \%$ in 2008 to $70.1 \%$ over the 8 -year period. There was also a significant decrease in the number of isolates of carbapenem-resistant $P$. aeruginosa (CRPA) during the study period with a reduction of $50.4 \%$ in Korea and $38.4 \%$ in Taiwan $(p<0.05)$ (Fig. 3b).

Carbapenem-resistant $A$. baumannii (CRAB) was more commonly isolated in Taiwan than in South Korea. The number of CRAB isolates initially increased in Taiwan and then decreased significantly with a total reduction of $49.2 \%$ from 2010 to $2015(p<0.05)$. In contrast, the number of CRAB isolates in Korea increased by $91.8 \%$ by the end of the study period (Fig. 3c). The proportion of CRAB among A. baumannii isolates was higher in Korea than in Taiwan, and increased from 2008 to 2015 in both countries.

\section{Discussion}

In the current study, we described the surveillance and IPC programs of Taiwan, South Korea and Japan. A variation in surveillance protocol, such as HAI case definition and surveillance items was found among the three countries although these protocols were similar to those employed by the HAI-net and NHSN. There were also common IPC strategies shared by the three countries, but each with special emphasis on different aspects of IPC. We also compared the rates of HAI and the most common causative pathogens as reported by the three surveillance systems. There was a 53\% decline in overall $\mathrm{HAI}$ in the surveyed ICUs of all three countries over the
8 -year period. The overall incidence densities of HAI in Taiwan, Korea, and Japan in 2015 were 5.0, 2.8, and 2.7 per 1000 patient-days, respectively. These rates are comparable to HAI-net (2.6 per 1000 patient-days), and substantially lower than those of developing countries, as shown in Table 3 [2, 12-15].

We believe that essential elements that contributed to the sustained decrease in the incidence of HAI in Taiwan, Korea and Japan were the national surveillance programs combined with improvement in IPC practices [16]. In Korea, there was a significant decline in device-associated HAI in association with the implementation of the KONIS program [17]. National IPC programs such as hand hygiene, care bundles, antimicrobial stewardships, and environmental hygiene have been shown to effectively reduce HAI and infections caused by AMR pathogens [7, 18-20]. In Taiwan, hand hygiene program over a 4-year period were found to reduce HAI in ICU by $17.2 \%$ and BSI by $12.7 \%$ [20], and care bundles to further reduce CAUTI and CLABSI by 22.7 and $12.2 \%$, respectively [21, 22]. In Korea, a multicentre study found that VAP rate decreased from 4.08 to 1.16 cases per 1000 ventilator-days following 3 months of bundle intervention [23]. Evidence-based IPC practices have been shown to be cost-saving and effective in preventing HAI $[20,24]$. Adoption of these practices to reduce HAI burden might be helpful for many Asian countries, which are facing problems such as rising healthcare costs and inefficient healthcare insurance systems [25].

Appointment of infection control professionals or infection control committees is a common strategy across the three countries (Fig. 1, Additional file 2: Table S2). In Japan, one serious fundamental obstacle before 2010 was the lack of personnel dedicated to IPC. In 2010, Japan revised medical reimbursement system and provided 10 


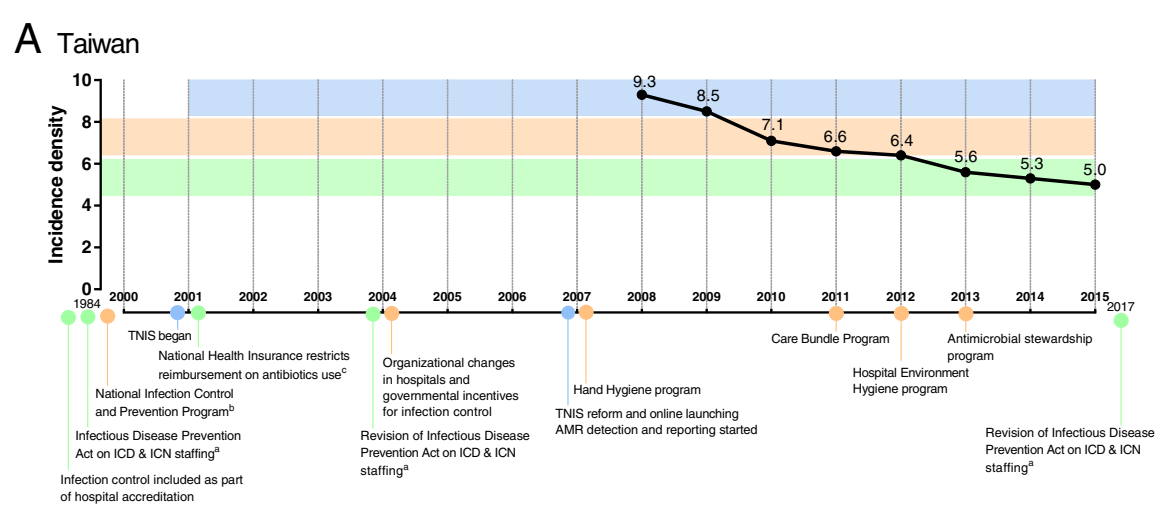

\section{B South Korea}

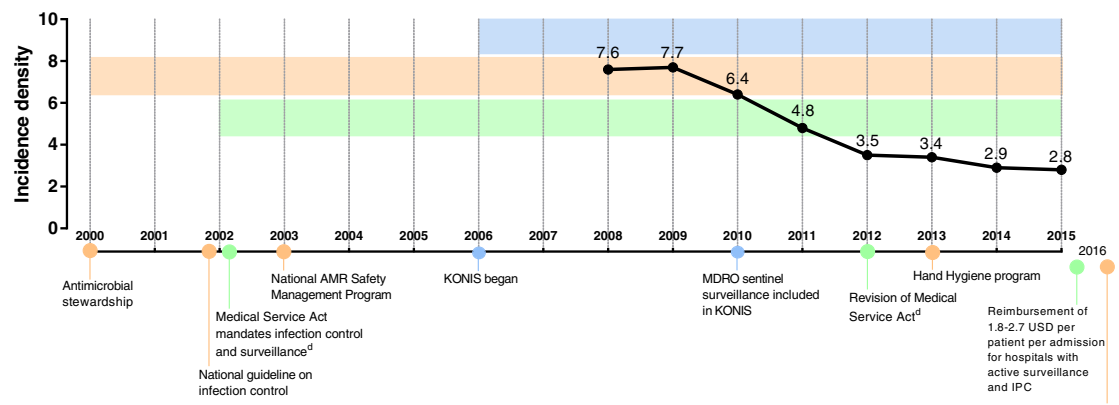

C Japan

National AMR Management

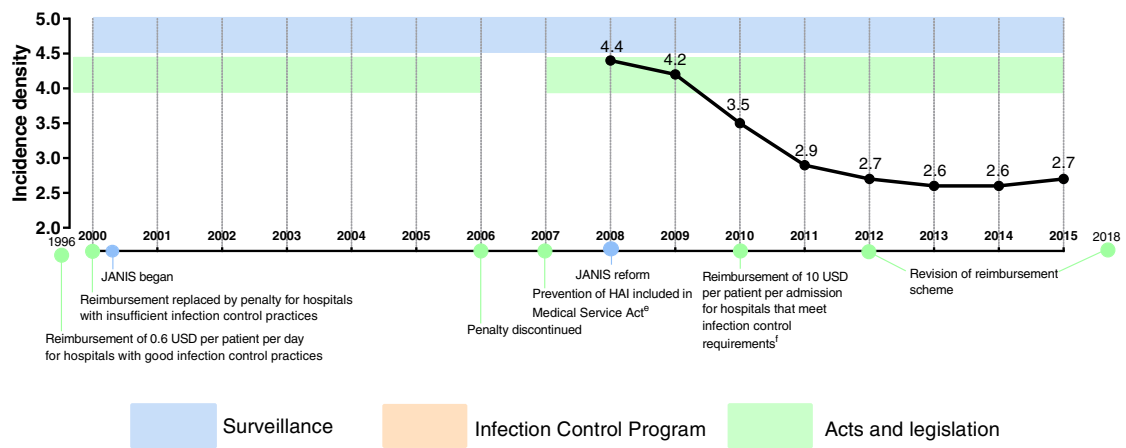

Fig. 1 Incidence densities of healthcare-associated infections in intensive care units across Taiwan, South Korea, and Japan from 2008 to 2015. Abbreviations: AMR: antimicrobial-resistance; HAl: healthcare-associated infections; ICN: infection control nurse; ICP: infection control personnel; IPC: infection prevention and control; JANIS: Japan Nosocomial Infection Surveillance; ICD: infection control doctor; KONIS: Korean National Healthcare-associated Infection Surveillance; MDRO: multi-drug resistant organisms; TNIS: Taiwan Nosocomial Infection Surveillance. ${ }^{a}$ In 1984 , every teaching hospital in Taiwan was required to have one ICN per 300 hospital beds. In 2004, hospitals with more than 500 beds are required to have at least one ICD, and hospitals with more than 300 beds are required to have at least one ICN per 250 beds. In 2017, hospitals with more than 500 beds are encouraged to have one ICD for every 300 beds and one ICN for every 250 beds (Table 1). ${ }^{b}$ Included training healthcare staff, establishing infection control committees, and formulating hospital policies. ${ }^{c}$ Restricts use of antimicrobials in ambulatory patients with upper respiratory infections but without evidence of bacterial infection. ${ }^{d}$ Act 29 specifies that IPC are the duties of hospitals with more than 300 beds. Act 47 mandates IPC as part of hospital accreditation. In 2012, hospitals with more than 200 beds are required to appoint an infection control committee and at least one full-time experienced staff (Table 1). ${ }^{\text {e }}$ Japanese medical law obligated all health care institutions to implement operational safety measures against HAl, which includes IPC guidelines, IPC training, and disease reporting. ${ }^{f}$ Hospitals should have an infection control team that consists of ICN, ICD, infection control pharmacist and infection control microbiology technologist. Hospitals should also have an IPC policy and antimicrobial stewardship program (Table 1). a Taiwan; b South Korea; c Japan

USD per patient per admission if a hospital payed the annual cost for the designated work hours for infection control personnel which included certificated nurse, doctor, pharmacist and medical technician/microbiologist. IPC incentives through reimbursement policies were revised in
2012 and 2018, as described in Additional file 2: Table S2. Such a scheme encourages hospitals dedicated certificated personnel to participate in IPC (Table 1). Other than manpower, personnel training and resource infrastructure are essential for surveillance and prevention of HAI [26, 27]. 


\section{A Catheter-associated urinary tract infections}

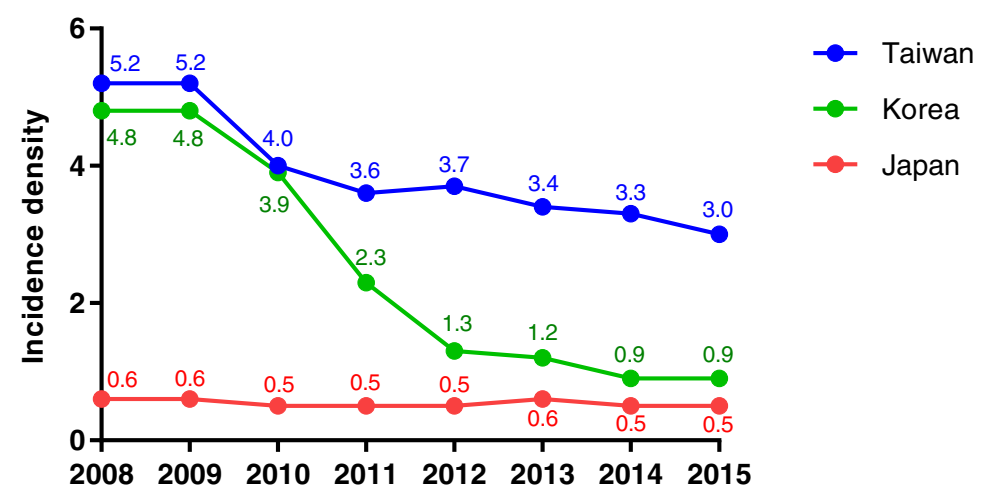

B Central line-associated bloodstream infections

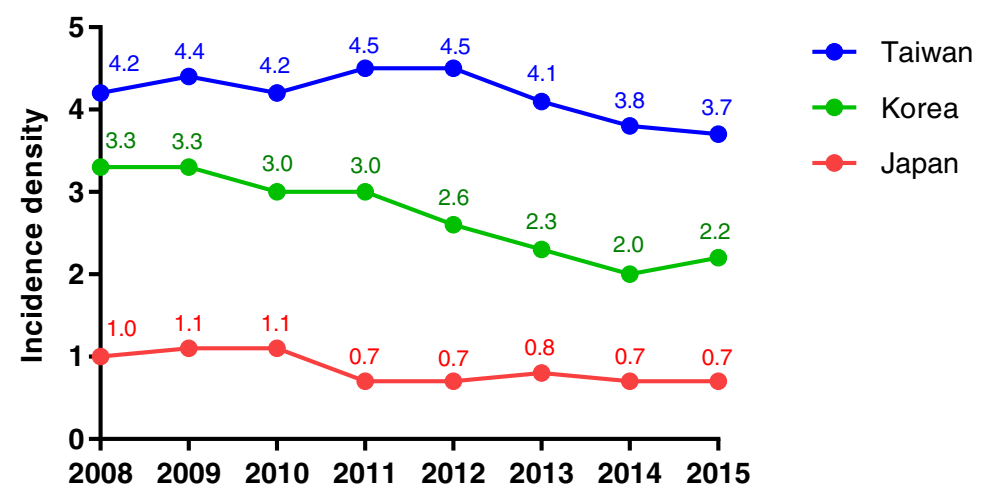

C Ventilator-associated pneumonia

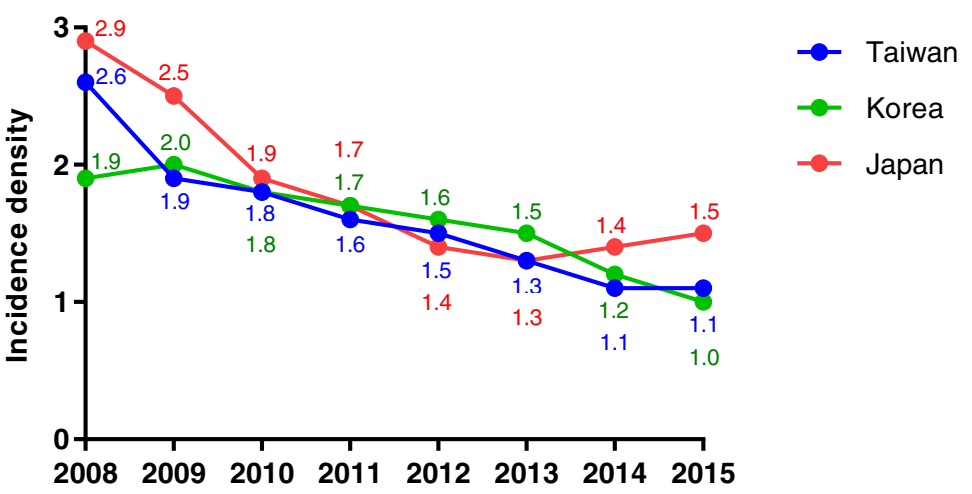

Fig. 2 Annual trends of device-associated infections in intensive care units from 2008 to 2015. Data are presented as episodes per 1000 device-days (Taiwan, Korea) or episodes per 1000 patient-days (Japan; data comprised urinary tract infections, central line-associated bloodstream infections and ventilatorassociated pneumonia). a Catheter-associated urinary tract infections; b Central line-associated bloodstream infections; c Ventilator-associated pneumonia

During the study period, financial incentives to support IPC programs were employed by Korea and Japan. Japan switched its reimbursement system to a penalty system in 2000 , and then changed it back to the current reward system in 2010. This suggests that a supportive environment that encourages IPC practices might be better than one that punishes for wrongdoing, and should be fostered by national authorities for effective prevention of HAI [27]. Correspondingly, such a difference in reimbursement may have well influenced the outcomes of HAI in Taiwan, Korea and Japan.

Changes in case definition might have contributed to the observed HAI trends. For example, the newer definition for UTI established in 2009 would probably have 
Table 2 Common causative pathogens of healthcare-associated infections in intensive care units enrolled in the national surveillance systems of Taiwan, South Korea, and Japan in 2015

\begin{tabular}{|c|c|c|c|c|c|c|}
\hline Rank & Organism & Proportion & Organism & Proportion & Organism & Proportion \\
\hline $\begin{array}{l}\text { Urinary Tract } \\
\text { Infections }^{a}\end{array}$ & Taiwan $(N=3990)$ & & South Korea $(N=760)$ & & Japan $(N=202)$ & \\
\hline 1 & Escherichia coli & $19.8 \%$ & Escherichia coli & $17.6 \%$ & Escherichia coli & $37.6 \%$ \\
\hline 2 & Candida albicans & $16.9 \%$ & Candida albicans & $12.6 \%$ & Pseudomonas aeruginosa & $16.3 \%$ \\
\hline 3 & Enterococcus faecium & $8.5 \%$ & Enterococcus faecalis & $9.5 \%$ & Candida albicans & $7.9 \%$ \\
\hline 4 & Pseudomonas aeruginosa & $7.4 \%$ & Enterococcus faecium & $9.3 \%$ & Klebsiella pneumoniae & $6.9 \%$ \\
\hline 5 & Klebsiella pneumoniae & $7.3 \%$ & Klebsiella pneumoniae & $8.6 \%$ & Enterococcus faecalis & $6.4 \%$ \\
\hline $\begin{array}{l}\text { Bloodstream } \\
\text { Infections }\end{array}$ & Taiwan $(N=4138)$ & & South Korea $(N=1288)$ & & $\operatorname{Japan}^{\mathrm{b}}(N=268)$ & \\
\hline 1 & Acinetobacter baumannii & $10.4 \%$ & Enterococcus faecium & $14.7 \%$ & Staphylococcus epidermidis & $15.7 \%$ \\
\hline 2 & Klebsiella pneumoniae & $9.6 \%$ & Staphylococcus aureus & $14.2 \%$ & Staphylococcus aureus & $13.0 \%$ \\
\hline 3 & Enterococcus faecium & $7.2 \%$ & Acinetobacter baumannii & $12.6 \%$ & Coagulase negative staphylococci & $10.1 \%$ \\
\hline 4 & Staphylococcus aureus & $6.5 \%$ & Coagulase negative staphylococci & $12.0 \%$ & Serratia marcescens & $5.6 \%$ \\
\hline 5 & Candida albicans & $6.2 \%$ & Enterococcus faecalis & $7.3 \%$ & & \\
\hline Pneumonia & Taiwan $(N=1397)$ & & South Korea $(N=554)$ & & $\operatorname{Japan}^{\mathrm{C}}(N=650)$ & \\
\hline 1 & Pseudomonas aeruginosa & $22.5 \%$ & Acinetobacter baumannii & $34.5 \%$ & Staphylococcus aureus & $21.8 \%$ \\
\hline 2 & Acinetobacter baumannii & $18.0 \%$ & Staphylococcus aureus & $28.5 \%$ & Pseudomonas aeruginosa & $18.6 \%$ \\
\hline 3 & Klebsiella pneumoniae & $16.2 \%$ & Klebsiella pneumoniae & $9.4 \%$ & Klebsiella pneumoniae & $7.8 \%$ \\
\hline 4 & Staphylococcus aureus & $9.0 \%$ & Pseudomonas aeruginosa & $8.8 \%$ & Stenotrophomonas maltophilia & $6.8 \%$ \\
\hline 5 & Enterobacter species & $6.2 \%$ & Enterobacter aerogenes & $3.2 \%$ & & \\
\hline
\end{tabular}

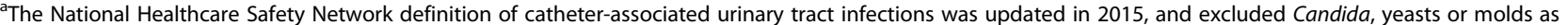
potential pathogens. Nevertheless, TNIS, KONIS and JANIS kept these pathogens and data are provided

'Japan's data on bloodstream infection represents central line-associated bloodstream infections

'Japan's data on pneumonia represents ventilator-associated pneumonia

excluded cases that might have been classified as HAI under the older definition [28]. Nevertheless, based on the consistent decline of HAI incidence across all infection categories, it is unlikely that modifications in case definition can explain the remarkable decrease in HAI trends.

Substantial variation exists for causative pathogens of HAI across the three countries. This variability could be due to a number of factors, including baseline characteristics of participating hospitals and ICUs, variation in diagnostic standards and case definitions, geography and climate, and IPC practices. For example, Japan's BSI was dominated by staphylococci (39.9\%) possibly because its reports were limited to device-associated modules in BSI. An interesting variation that is likely not attributable to systemic differences was noted for A. baumannii, which was isolated commonly from Taiwan and Korea but rarely from Japan. Results from HAI-net seem to support this notion, with higher proportions of HAI caused by Acinetobacter spp. in some countries [13].

Our study showed a general decrease in isolates of important AMR species: MRSA, CRPA and CRAB even though the number of participating ICUs has expanded from 2008 to 2015. This downward trend is likely due to hand hygiene to prevent cross-transmission of AMR pathogens, care bundles to prevent device- or procedure-associated infections, and antimicrobial stewardship programs to mitigate the selection pressure implemented in these countries [7, 18-20, 29]. A recent meta-analysis reported that antimicrobial stewardship programs in Asia reduced overall antimicrobial consumption by $9.74 \%$ and incidence density of important AMR pathogens such as MRSA by 0.9 to 1.4 isolates per 1000 patient-days [19]. Expenditure associated with antimicrobial prescription and hospitalization were also found to decrease by a range of 9.7 to $58.1 \%$. These findings highlight the efficacy and importance of antimicrobial stewardship programs in combating the rise of AMR pathogens.

While surveillance of HAI may provide important feedback for IPC efforts, the high costs in establishing and maintaining the system may preclude many countries from undertaking such an ordeal. Introducing information technology in surveillance systems may help reduce labor intensive and increase the efficiency of surveillance [30-33]. In Asia, National Taiwan University Hospital has established a web-based real-time surveillance system based on algorithms for AMR pathogens, UTI and BSI. The surveillance system is sophisticated in its ability to integrate and analyse several data sources $[32,33]$. Their studies and a recent 


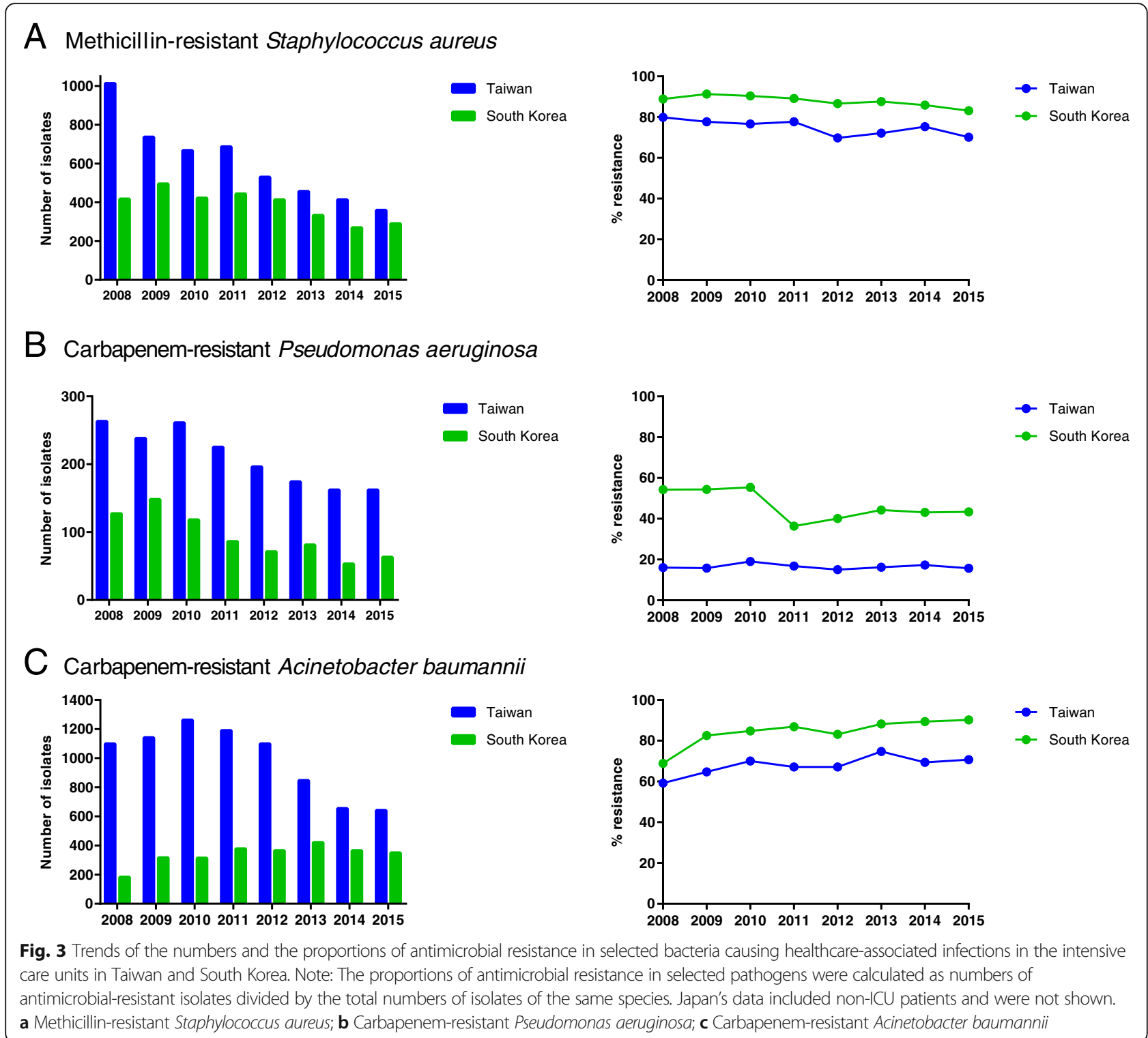

systematic review of the literature demonstrated that adopting electronic surveillance software yields considerable time savings pertaining to case findings, data collection, case ascertainment and classification while maintaining high levels of sensitivity and specificity [31-33]. Thus, information technology may represent an opportunity for countries seeking to establish HAI surveillance and overcome the gaps of human resources.

Our study provides a framework for other countries to establish or improve surveillance and IPC programs. Further studies on cost-effectiveness of these strategies will be helpful to relevant stakeholders as they allocate and prioritize budget for infection control. Our work also serves as the foundation for possible regional collaborations in East Asia or in greater Asia. Standardization of protocols will allow inter-country comparison and benchmarking.
For Europe, the similarities and differences in HAI trends between our study and the HAI-net re-affirmed the need for continual surveillance and IPC efforts.

The strengths of this study were our ability to obtain an overview of the surveillance and IPC programs of Taiwan, Korea, and Japan that were seldom described in past reports. We were also able to obtain comprehensive HAI data from their surveillance systems and compare these data with Western developed countries and developing countries worldwide. The limitations were the need to use open access datasets. This restricted our ability to assess and compare HAI epidemiology comprehensively across the three countries. JANIS only releases data on UTI, CLABSI, and VAP in its surveillance reports. Information on the other infection modules: CAUTI, BSI, and HAP were unavailable. We were unable to comprehensively 
Table 3 Comparison of healthcare-associated infections in intensive care units across different geographic regions

\begin{tabular}{|c|c|c|c|c|c|c|c|c|c|}
\hline \multirow[b]{2}{*}{ Countries/Regions (surveillance system) } & \multirow[b]{2}{*}{$\begin{array}{l}\text { Data source or type of } \\
\text { study }\end{array}$} & \multirow[b]{2}{*}{ Year } & \multirow[b]{2}{*}{ Overall $^{a}$} & \multicolumn{3}{|c|}{$\begin{array}{l}\text { Site-specific HAl } \\
\text { (per } 1000 \\
\text { patient-days) }\end{array}$} & \multicolumn{3}{|c|}{$\begin{array}{l}\text { Device-associated HAl } \\
\text { (per } 1000 \text { device-days) }\end{array}$} \\
\hline & & & & $\overline{U T I^{\mathrm{b}}}$ & BSI & HAP & $\overline{C A U T I^{b}}$ & CLABSI & VAP \\
\hline Taiwan (TNIS) & National surveillance & 2015 & $5.0(8514 / 1692998)$ & 2.1 & 2.1 & 0.8 & 3.0 & 3.7 & 1.1 \\
\hline South Korea (KONIS) & National surveillance & 2015 & $2.8^{c}(2608 / 945605)$ & 0.8 & 1.3 & 0.7 & 0.9 & 2.2 & 1.0 \\
\hline Japan (JANIS) & National surveillance & 2015 & $2.7^{d}(952 / 347386)$ & 0.5 & - & - & - & $0.7^{\mathrm{e}}$ & $1.5^{\mathrm{e}}$ \\
\hline USA (NHSN) [12] & National surveillance & 2012 & $1.6^{f}(37872 / 23344616)$ & - & - & - & 2.1 & 1.1 & 1.4 \\
\hline Europe (HAl-net) [13] & National surveillance & 2015 & $2.6(15821 / 6177114)$ & 1.1 & 2.0 & 4.0 & 3.6 & 3.6 & 10.0 \\
\hline Southeast Asia [2] & Meta-analysis $^{9}$ & 2000-2012 & $20.0^{h}(16.9450 / 26681)$ & - & - & - & 8.9 & 4.7 & 14.7 \\
\hline $\begin{array}{l}\text { Developing countries } \\
\text { worldwide [14] }\end{array}$ & Meta-analysis ${ }^{9}$ & 1995-2008 & $47.9^{\text {h }}(28.54250 / 148893)$ & - & - & - & 9.8 & 11.3 & 22.9 \\
\hline $\begin{array}{l}\text { Developing countries } \\
\text { worldwide (INICC) }{ }^{i} \text { [15] }\end{array}$ & Multi-center study & 2010-2015 & - & - & - & - & 5.1 & 4.1 & 13.1 \\
\hline
\end{tabular}

Abbreviations: BSI bloodstream infections, CAUTI catheter-associated urinary tract infections, CLABSI central line-associated bloodstream infections, HAI healthcareassociated infections, HAI-net Healthcare-associated Infections Surveillance Network (Europe), HAP hospital-acquired pneumonia, ICU intensive care units, INICC International Nosocomial Infection Control Consortium (developing countries worldwide), NHSN National Healthcare Safety network (USA), UTI urinary tract infections, VAP ventilator-associated pneumonia

${ }^{\text {a } D a t a}$ are pooled mean of site-specific HAI such as UTI, BSI, and HAP or otherwise specified, and computed from raw data provided in the reports. Thus, all these data should be interpreted appropriately

${ }^{b}$ The NHSN CAUTI definition was updated in 2015 and excluded Candida, yeasts or molds as potential CAUTI pathogens. Nevertheless, TNIS, KONIS and JANIS kept these pathogens and data are provided

'Data were collected during July 2015-June 2016

dData are pooled means of UTI, CLABSI and VAP

'Data were calculated by episodes/1000 patient-day

fData are pooled means of CAUTI, CLABSI and VAP

Infection frequencies reported in high-quality studies were greater than those from low-quality studies

heights were given to different studies to compute the final data. Unweighted raw data were derived from the original article and denoted in parenthesis

'Data were prospectively collected from 861,284 patients in 703 ICUs from 50 countries

describe the complete pathogen rankings and AMR profiles for each country, because these data were unavailable on some surveillance systems. There are differences in protocols employed by each surveillance system, such as JANIS, which calculated device-associated infections differently. Standardization of protocols should allow for inter-country comparison. Furthermore, we need to include antibiotic use in future studies because of their critical impact on development of resistance. Finally, there were differences in the types of the hospitals enrolled in the three systems, wide variation of hospital participation rates $(6.8 \%$ in Japan and $100 \%$ in Taiwan), and thus, discrepancies in hospital coverage rates $(1.9 \%$ in Japan and $21.2 \%$ in Taiwan). Therefore, data presented here cannot be generalized to the entire 3 countries.

\section{Conclusions}

We found that national surveillance data obtained from Taiwan, South Korea, and Japan from 2008 to 2015 was associated with a $53.0 \%$ reduction in HAI in surveyed ICUs. There were differences among the countries in surveillance protocols, hospital coverage rates, national IPC programs, distribution of invading microorganisms and antibiotic resistance. The overall decrease in HAI appears to be due to improved surveillance coupled with a series of interventions in each country. We propose that a regional HAI network be established in East Asia similar to Europe's HAI-net. Such a coordinated effort should enable greater regional collaborations and development of joint strategies as we learn from one another.

\section{Additional files}

Additional file 1: Table S1. The number of participating hospitals and intensive care units of national healthcare-associated infection surveillance system in each country from 2008 to 2015. (DOCX 33 kb)

Additional file 2: Table S2. National infection prevention and control policies and programs initiated, implemented or extended in Taiwan, South Korea, and Japan. (DOCX 59 kb)

Additional file 3: Table S3. Common causative pathogens of healthcareassociated urinary tract infections in intensive care units enrolled in national surveillance systems in Taiwan, South Korea, and Japan in 2015. (DOCX 36 kb)

Additional file 4: Table S4. Common causative pathogens of healthcareassociated bloodstream infections in intensive care units enrolled in national surveillance systems in Taiwan, South Korea, and Japan in 2015. (DOCX 36 kb)

Additional file 5: Table S5. Common causative pathogens of healthcareassociated pneumonia in intensive care units enrolled in national surveillance systems in Taiwan, South Korea, and Japan in 2015. (DOCX 36 kb)

\section{Abbreviations}

AMR: Antimicrobial resistance; AS: Antimicrobial stewardship;

BSI: Bloodstream infection; CAUTI: Catheter-associated urinary tract infection; CLABSI: Central line-associated bloodstream infection; CRPA: Carbapenemresistant Pseudomonas aeruginosaCRABCarbapenem-resistant Acinetobacter baumannii; FTE: Full-time equivalent; HAl: Healthcare-associated infections; HAl-net: European Healthcare-associated Infections Surveillance Network; 
HAP: Hospital-acquired pneumonia; IC: Infection control; ICD: Infection control doctor; ICN: Infection control nurse; ICP: Infection control personnel; ICU: Intensive care units; INICC: International Nosocomial Infection Control Consortium; IPC: Infection prevention and control; JANIS: Japan Nosocomial Infection Surveillance; KONIS: Korean National Healthcare-associated Infection Surveillance; MRSA: Methicillin-resistant Staphylococcus aureus; NHSN: National Healthcare Safety Network; TNIS: Taiwan Nosocomial Infection Surveillance; UTI: Urinary tract infection; VAP: Ventilator-associated pneumonia

\section{Acknowledgements}

We thank Calvin M. Kunin for his critical review of the manuscript.

\section{Funding}

No funding support.

\section{Availability of data and materials}

All data generated during and/or analysed during the current study are publicly available on the respective published reports or included in this published article.

\section{Authors' contributions}

Part of data were presented by $\mathrm{CH}$ Chiang at the International Conference on Prevention and Infection Control, 20-23 June 2017, Geneva, Switzerland. YC Chen coordinated and designed the study, and proofread the manuscript. CH Chiang, TS Yang and K Matsuda collected and analysed the data. SC Pan supervised statistical analysis. CH Chiang, SC Pan and YC Chen prepared the manuscript. FY Chang and SC Chang were involved in national infection control and prevention programs during the study period. HB Kim, $\mathrm{YH}$ Choi and other authors provided relevant information to consolidate the contents of the manuscript.

\section{Ethics approval and consent to participate}

The protocol was approved by the Research Ethics Committee of the National Taiwan University Hospital and complied with the categories for exemption (201710001 W).

\section{Consent for publication}

Not applicable

\section{Competing interests}

The authors declare that they have no competing interests.

\section{Publisher's Note}

Springer Nature remains neutral with regard to jurisdictional claims in published maps and institutional affiliations.

\section{Author details}

${ }^{1}$ College of Medicine, National Taiwan University, Taipei, Taiwan.

¿Department of Internal Medicine, National Taiwan University Hospital, Taipei, Taiwan. ${ }^{3}$ Faculty of Medicine, Osaka University, Osaka, Japan. ${ }^{4}$ Department of Internal Medicine, Seoul National University College of Medicine, Seoul, Republic of Korea. ${ }^{5}$ Division of Infectious Diseases, Seoul National University Bundang Hospital, Seongnam, Republic of Korea. ${ }^{6}$ Department of Infectious Diseases, Ajou University School of Medicine, Suwon, Republic of Korea. ${ }^{7}$ Department of Infection Control Science, Juntendo University Faculty of Medicine, Tokyo, Japan. ${ }^{8}$ Center for Infection Control, National Taiwan University Hospital, Taipei, Taiwan. ${ }^{9}$ National Institute of Infectious Diseases and Vaccinology, National Health Research Institutes, Miaoli County, Taiwan. ${ }^{10}$ Division of Infectious Diseases and Tropical Medicine, Department of Internal Medicine, Tri-Service General Hospital, National Defense Medical Center, Taipei, Taiwan.

Received: 29 July 2018 Accepted: 12 October 2018 Published online: 07 November 2018

\section{References}

1. European Centre for Disease Prevention and Control. Healthcare-associated Infections Surveillance Network. Available at: https://ecdc.europa.eu/en/ about-us/partnerships-and-networks/disease-and-laboratory-networks/hainet. Assessed 14 Apr 2018.
2. Ling ML, Apisarnthanarak A, Madriaga G. The burden of healthcareassociated infections in Southeast Asia: a systematic literature review and meta-analysis. Clin Infect Dis. 2015;60(11):1690-9.

3. Mehta $Y$, Jaggi N, Rosenthal VD, Kavathekar M, Sakle A, Munshi N, et al. Device-associated infection rates in 20 cities of India, data summary for 2004-2013: findings of the international nosocomial infection control consortium. Infect Control Hosp Epidemiol. 2016;37(2):172-81.

4. Tao L, Hu B, Rosenthal VD, Gao X, He L. Device-associated infection rates in 398 intensive care units in Shanghai, China: international nosocomial infection control consortium (INICC) findings. Int J Infect Dis. 2011;15(11):e774-80.

5. World Health Organization. Report on the burden of endemic health careassociated infection worldwide: clean care is safer care. Available at: http:// apps.who.int/iris/bitstream/handle/10665/80135/9789241501507_eng.pdf; jsessionid=D87704F8824B725B0E90EBA22DE3BAAE? sequence $=1$. Accessed 14 Apr 2018.

6. Centers for Disease Control, R.O.C (Taiwan). Nosocomial Infections Surveillance System. Available at: http://www.cdc.gov.tw/english/info. aspx?treeid=00ed75d6c887bb27\&nowtreeid=f0131176aa46d5db\&tid= 1A8C498AF5F8AF5D. Accessed 14 Apr 2018.

7. Tseng SH, Lee CM, Lin TY, Chang SC, Chuang YC, Yen MY, et al. Combating antimicrobial resistance: antimicrobial stewardship program in Taiwan. $J$ Microbiol Immunol Infect. 2012;45(2):79-89.

8. Korean Society for Healthcare-associated Infection Control and Prevention. Korean Nosocomial Infections Surveillance System. Available at: http://www. koshic.org/main/main.html. Accessed 14 Apr 2018.

9. Choi JY, Kwak YG, Yoo H, Lee SO, Kim HB, Han SH, et al. Trends in the incidence rate of device-associated infections in intensive care units after the establishment of the Korean nosocomial infections surveillance system. J Hosp Infect. 2015;91(1):28-34.

10. Choi JY, Kwak YG, Yoo H, Lee SO, Kim HB, Han SH, et al. Trends in the distribution and antimicrobial susceptibility of causative pathogens of device-associated infection in Korean intensive care units from 2006 to 2013: results from the Korean nosocomial infections surveillance system (KONIS). J Hosp Infect. 2016;92(4):363-71.

11. Ministry of Health, Labour and Welfare, Japan. Japan Nosocomial Infections Surveillance. Available at: https://janis.mhlw.go.jp/report/icu.html. Accessed 14 Apr 2018.

12. Centers for Disease Control and Prevention, USA. National Healthcare Safety Network Reports. Available at: https://www.cdc.gov/nhsn/datastat/index. html. Accessed 14 Apr 2018.

13. European Centre for Disease Prevention and Control. Healthcare-associated infections acquired in intensive care units - Annual Epidemiological Report for 2015. Available at: https://ecdc.europa.eu/en/publications-data/ healthcare-associated-infections-acquired-intensive-care-units-annual. Accessed 14 Apr 2018

14. Allegranzi B, Bagheri Nejad S, Combescure C, Graafmans W, Attar H, Donaldson $L$, et al. Burden of endemic health-care-associated infection in developing countries: systematic review and meta-analysis. Lancet. 2011; 377(9761):228-41.

15. Rosenthal VD, Al-Abdely HM, El-Kholy AA, AlKhawaja SAA, Leblebicioglu H, Mehta $Y$, et al. International nosocomial infection control consortium report, data summary of 50 countries for 2010-2015: device-associated module. Am J Infect Control. 2016;44(12):1495-504.

16. Haley RW, Culver DH, White JW, Morgan WM, Emori TG, Munn VP, et al. The efficacy of infection surveillance and control programs in preventing nosocomial infections in US hospitals. Am J Epidemiol. 1985;121(2):182-205.

17. Kim EJ, Kwak YG, Park SH, Kim SR, Shin MJ, Yoo HM, et al. Trends of device utilization ratios in intensive care units over 10-year period in South Korea: Device utilization ratio as a new aspect of surveillance. J Hosp Infect. 2017. doi: https://doi.org/10.1016/j.jhin.2017.10.007. [Epub ahead of print]. pii: S0195-6701(17)30547-9.

18. Price L, MacDonald J, Melone L, Howe T, Flowers P, Currie K, et al. Effectiveness of national and subnational infection prevention and control interventions in high-income and upper-middle-income countries: a systematic review. Lancet Infect Dis. 2018;18(5):e159-71.

19. Honda H, Ohmagari N, Tokuda Y, Mattar C, Warren DK. Antimicrobial stewardship in inpatient settings in the Asia Pacific Region: a systematic review and meta-analysis. Clin Infect Dis. 2017;64(suppl_2):S119-26.

20. Chen YC, Sheng WH, Wang JT, Chang SC, Lin HC, Tien KL, et al. Effectiveness and limitations of hand hygiene promotion on decreasing healthcare-associated infections. PLoS One. 2011;6(11):e27163. 
21. Lai CC, Lee CM, Chiang HT, Hung CT, Chen YC, Su LH, et al. Implementation of a national bundle care program to reduce catheter-associated urinary tract infection in high-risk units of hospitals in Taiwan. J Microbiol Immunol Infect. 2017:50(4):464-70.

22. Lai CC, Cia CT, Chiang HT, Kung YC, Shi ZY, Chuang YC, et al. Implementation of a national bundle care program to reduce central line-associated bloodstream infections in intensive care units in Taiwan. J Microbiol Immunol Infect. 2017. doi: https://doi.org/10.1016/j.jmii.2017.10.001. [Epub ahead of print]. pii: S1684-1182(17)30231-1.

23. Eom JS, Lee MS, Chun HK, Choi HJ, Jung SY, Kim YS, et al. The impact of a ventilator bundle on preventing ventilator-associated pneumonia: a multicenter study. Am J Infect Control. 2014;42(1):34-7.

24. Umscheid CA, Mitchell MD, Doshi JA, Agarwal R, Williams K, Brennan PJ, Estimating the proportion of healthcare-associated infections that are reasonably preventable and the related mortality and costs. Infect Control Hosp Epidemiol 2011;32(2):101-1.

25. Organisation for Economic Co-operation and Development. Health at a Glance 2017 OECD Indicators. Available at: https://doi.org/10.1787/health_ glance-2017-en. Accessed 14 Apr 2018.

26. Kwak YG, Lee SO, Kim HY, Kim YK, Park ES, Jin HY, et al. Risk factors for device-associated infection related to organisational characteristics of intensive care units: findings from the Korean nosocomial infections surveillance system. J Hosp Infect. 2010;75(3):195-9.

27. Sakamoto F, Sakihama T, Saint S, Greene MT, Ratz D, Tokuda Y. Health careassociated infection prevention in Japan: the role of safety culture. Am J Infect Control. 2014;42(8):888-93.

28. Healthcare Infection Control Practices Advisory Committee. Guideline for prevention of catheter-associated urinary tract infections 2009. Available at: https://www.cdc.gov/infectioncontrol/pdf/guidelines/cauti-guidelines.pdf. Accessed 14 Apr 2018

29. Krein SL, Greene MT, Apisarnthanarak A, Sakamoto F, Tokuda Y, Sakihama T, et al. Infection Prevention Practices in Japan, Thailand, and the United States: Results From National Surveys. Clin Infect Dis. 2017;64(suppl_2):S105-11.

30. Van Mourik MSM, Perencevich EN, Gastmeier P, Bonten MJM. Designing surveillance of healthcare-associated infections in the era of automation and reporting mandates. Clin Infect Dis. 2018;66(6):970-6.

31. Russo PL, Shaban RZ, Macbeth D, Carter A, Mitchell BG. Impact of electronic healthcare-associated infection surveillance software on infection prevention resources: a systematic review of the literature. J Hosp Infect. 2018;99(1):1-7. https://doi.org/10.1016/j.jhin.2017.09.002 Epub 2017 Sep 8.

32. Tseng YJ, Wu JH, Ping XO, Lin HC, Chen YY, Shang RJ, et al. A web-based multidrug-resistant organism surveillance and outbreak detection system with rule-based classification and clustering. J Med Internet Res. 2012;14(5):e131.

33. Tseng YJ, Wu JH, Lin HC, Chen MY, Ping XO, Sun CC, et al. A web-based, hospital-wide health care-associated bloodstream infection surveillance and classification system: development and evaluation. JMIR Med Inform. 2015 3(3):e31.

Ready to submit your research? Choose BMC and benefit from:

- fast, convenient online submission

- thorough peer review by experienced researchers in your field

- rapid publication on acceptance

- support for research data, including large and complex data types

- gold Open Access which fosters wider collaboration and increased citations

- maximum visibility for your research: over $100 \mathrm{M}$ website views per year

At $\mathrm{BMC}$, research is always in progress.

Learn more biomedcentral.com/submissions 